\title{
Ltspice Simulation of Non Linear Technique SSHI Serial and SSHI Parallel of Piezoelectric Vibration Energy Harvesting
}

\author{
Abderrahim Mountaciri, El Mostafa Makroum, My Abdelkader Youssefi
}

\begin{abstract}
: in this paper, a simple but effective proposal for piezoelectric energy collectors. synchronized switching harvesting in the SSIH technique (synchronized switch harvesting on parallel inductor consists in placing a switch which will be commanded on closing at the instant when the amplitude of the vibrations passes through the extreme this technique makes it possible to increase the power harvested from a ratio of 8 compared to the power of a harvester based on ac dc converter similarly the SSIH command (synchronized switch harvesting on inductor for LT SPICEs-based simulations of the two techniques is carried out finally a comparison with respect to the standard structure of energy harvesting is made in order to validate theoretical concepts.
\end{abstract} FBR

Keywords: harvesting, SSHI, piezoelectric, WSN, LTSPICE,

\section{INTRODUCTION}

the recovery of vibration energy can also be carried out by magnetic or capacitive devices [1], but it is the piezoelectric solution that is the most promising because it has the highest electromechanical coupling coefficient, requiring no polarization and the material is well suited to micro systems manufacturing technologies . piezoelectric energy collectors (PEH) has emerged as a leading theme of researchers whose interest continues to grow. the progress of low power components or design methodology reduced power consumption mobile, and therefore allow the feasibility of autonomous self-powered electronics devices. this opens up the possibility for completely self-powered devices, and the notion of small generators that produce enough power for low-power devices, such as wireless sensor network (WSN). table 1 gives a power consumption balance for WSN ambient vibrations are presented in many different environments such as automobiles, ildings, structures (bridges, railways), industrial machinery, etc since 2002, many studies have been published on the subject of energy recovery.

Manuscript received on January 30, 2021.

Revised Manuscript received on February 15, 2021.

Manuscript published on February 28, 2021

* Correspondence Author

Mountaciri Abderrahim*, Laboratoire d'Ingenierie, de Management Industriel et d'Innovation (LIMII), Faculte' des Sciences et techniques (FST), universite Hassan I, settat, morroco. Email: yahyamountaciri@gmail.com

Makroum El-Mostafa, Laboratoire d'Ingenierie,' de Management Industriel et d'Innovation (LIMII), Faculte' des Sciences et techniques (FST), universite Hassan I, settat, morroco. Email: elmostafa1980@gmail.com

My Abdelkader Youssefi, Laboratoire d'Ingenierie, ' de Management Industriel et d'Innovation (LIMII), Faculte' des Sciences et techniques (FST), universite Hassan I, settat, morroco. Email: ab.youssefi@gmail.com

(C) The Authors. Published by Blue Eyes Intelligence Engineering and Sciences Publication (BEIESP). This is an open access article under the CC BY-NC-ND license (http://creativecommons.org/licenses/by-nc-nd/4.0/) tang et al. and khaligh et al. [2] made a long synthesis and developed a state of the art for piezo electric vibration energy. collector it demonstrates the interest of researchers in this subject. in addition, piezoelectric materials have high power density power density of the piezoelectric generator collected the energy of the vibrations is about $250 \mu \mathrm{w} / \mathrm{cm} 3$. in comparison, the power density of the electrostatic generator which collected energy vibrations are only about $50 \mu \mathrm{w} / \mathrm{cm} 3$. the vibration-to-electricity converter can also be performed by electromagnetic transducers ,but the power density cannot be high the piezoelectric generator. piezoelectric technologies have received a lot of attention, as they have high electromechanical coupling and no requirement of external voltage source. table 1 give a comparison of the three technology for harvesting which are of piezoelectric, electrostatic and electromagnetic type the variables which appear in the energy density equation for piezoelectric transducers are the elastic limit of the material $\sigma \mathrm{y}$, the piezoelectric coupling coefficient $\mathrm{k}$ and the young $\mathrm{y}$ modulus in the case of the electrostatic transducer, $\varepsilon$ is the dielectric constant and $\mathrm{e}$ is the electric field between the plates. in the case of the electromagnetic transducer, B is the magnetic field and $\mu 0$ is the magnetic a vacum permeability. ambient vibrations are present in different environments such as automobiles, buildings, structures (bridges, railways), industrial machines, etc. table 2, gives values of the amplitude and frequency of the fundamental of the acceleration for different sources of vibration. these data are all the more important as the recovered power is proportional to the acceleration squared and inversely proportional to the frequency, as we will see below. the vibrations can be continuous, impulsive or intermittent: can be continuous, impulsive or intermittent:- continuous vibrations have a constant amplitude;- impulses relate to shocks;- intermittent have an amplitude which varies over time. continuous vibrations are the most attractive for energy recovery. various bridges are summarized in table 3 . the maximum acceleration of bridge vibrations reported by sazonov et al. is $0.55 \mathrm{~g}$; however, the maximum frequency (40 HZ) is recoded for the bridge reported by short and medium range bridges vibrate with a frequency generally between 2 and $8 \mathrm{HZ}$ and acceleration levels less than $0.1 \mathrm{~g}$ some

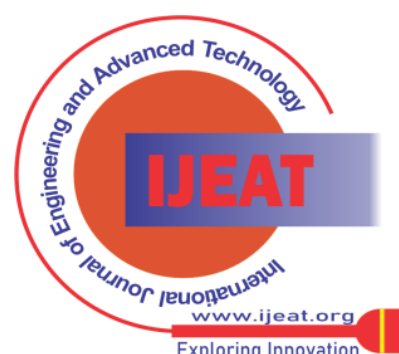




\section{Ltspice Simulation of Non Linear Technique SSHI Serial and SSHI Parallel of Piezoelectric Vibration Energy Harvesting}

Table 1- Summary of piezoelectric generators in WSN

\begin{tabular}{|c|c|c|c|c|c|c|}
\hline Reference & $P(\mu W)$ & $F(\mathbf{H z})$ & $A\left(\mathrm{~m} \mathrm{~s}^{-2}\right)$ & $M(g)$ & Volume $\left(\mathrm{mm}^{3}\right)$ & Details \\
\hline $\begin{array}{l}\text { Kymissis [44] } \\
\text { MIT (US) }\end{array}$ & 1300 & 0.9 & - & - & $16000^{\circ}$ & $\begin{array}{l}\text { PVDF stack located on } \\
\text { shoe insole driven by a } \\
\text { walking human }\end{array}$ \\
\hline Umeda [38] & $\begin{array}{l}19^{\circ} \text { (per } \\
\text { impact) }\end{array}$ & $\mathrm{N} / \mathrm{A}$ & $\mathrm{N} / \mathrm{A}$ & 1.73 & 214 & $\begin{array}{l}\text { Bronze/PZT disc } \\
\text { driven by impacts }\end{array}$ \\
\hline $\begin{array}{l}\text { Shenk [45] } \\
\text { MIT (US) }\end{array}$ & 8400 & 0.9 & $\mathrm{~N} / \mathrm{A}$ & $\mathrm{N} / \mathrm{A}$ & $25000^{2}$ & $\begin{array}{l}\text { PZT dimorph located } \\
\text { in heal of shoe driven } \\
\text { by a walking human }\end{array}$ \\
\hline Ramsay [50] & 2.3 & 1 & & & & $1.1 \mathrm{~mm} \times 1 \mathrm{~cm} \times 1 \mathrm{~cm}$ \\
\hline $\begin{array}{l}\text { White [55] } \\
\text { Southampton University (UK) }\end{array}$ & 2.1 & 80.1 & $2.3^{a}$ & 0.8 & 125 & Steel/screen printed PZT \\
\hline $\begin{array}{l}\text { Roundy [20] } \\
\text { Berkeley University (US) }\end{array}$ & 210 & 120 & 2.5 & $8.5^{4}$ & 1000 & $\begin{array}{l}\text { Brass/PZT/tungsten } \\
\text { cantilever generator }\end{array}$ \\
\hline $\begin{array}{l}\text { Roundy [20] } \\
\text { Berkeley University (US) }\end{array}$ & 375 & 120 & 2.5 & $9.2^{*}$ & 1000 & $\begin{array}{l}\text { Brass/PZT/tungsten } \\
\text { cantilever generator }\end{array}$ \\
\hline $\begin{array}{l}\text { Sodano [60] } \\
\text { Virginia Poly (US) }\end{array}$ & 11.9 & 30 & Not stated & 9.52 & $\begin{array}{l}\text { Total device } 1947 \text {, } \\
\text { active volume } 240\end{array}$ & $\begin{array}{l}\text { Mide Technology QP40 N } \\
\text { transducer clamped at one et }\end{array}$ \\
\hline $\begin{array}{l}\text { Duggirala [68] } \\
\text { Cornell Univensity (US) }\end{array}$ & 0.001 & 35 & $\mathbf{N} / \mathbf{A}$ & $\mathrm{N} / \mathrm{A}$ & $60^{\circ}$ & $\begin{array}{l}{ }^{63} \text { Ni radioisotope } \\
\text { Silicon/PZT cantilever }\end{array}$ \\
\hline $\begin{array}{l}\text { Bayrashev [113] } \\
\text { Minnesota University (US) }\end{array}$ & 80 & 5 & Not stated & $\begin{array}{l}15.6^{2} \text { (including } \\
\text { magnet) }\end{array}$ & $\begin{array}{l}2185 \text { (including } \\
\text { magnet) }\end{array}$ & $\begin{array}{l}\text { Terfenol-D/PZT/ } \\
\text { Terfenol-D composite }\end{array}$ \\
\hline $\begin{array}{l}\text { Marzencki }[69] \\
\text { Tima, France }\end{array}$ & $\begin{array}{l}0.1^{\mathrm{b}} \mathrm{AIN} \\
0.6^{\mathrm{b}} \mathrm{PZT}\end{array}$ & 900 & 9.81 & $1.1 \times 10^{-3}$ & $\begin{array}{l}2 \text { (whole chip) } \\
0.9 \text { (mass and } \\
\text { cantilever) }\end{array}$ & $\begin{array}{l}\text { Thin film AIN or PZT on } \\
\text { micromachined silicon } \\
\text { cantilever structure }\end{array}$ \\
\hline $\begin{array}{l}\text { Jeon [70] } \\
\text { Varian Korca, Korca IST, } \\
\text { Polychromix and MIT (US) }\end{array}$ & 1 & 13.9 & 106 & Not given & $0.027^{2}$ & $\begin{array}{l}\text { Micromachined silicon } \\
\text { device with IDT } \\
\text { electrodes }\end{array}$ \\
\hline
\end{tabular}

Table 2 - comparison of different harvesting technic

\begin{tabular}{|l|l|l|l|l|l|}
\hline & $\begin{array}{l}\text { Output } \\
\text { voltage }\end{array}$ & $\begin{array}{l}\text { Density } \\
\text { Energy min } \\
\left(\mu \mathrm{j} / \mathbf{c m}^{\mathbf{3}}\right)\end{array}$ & $\begin{array}{l}\text { Density } \\
\text { energy min } \\
\left(\mu \mathrm{j} / \mathbf{c m}^{\mathbf{3}}\right)\end{array}$ & disadvantages & advantages \\
\hline Pezos electric & $\mathbf{u}=\frac{\mathbf{k} \boldsymbol{\sigma}_{\mathbf{y}}{ }^{2}}{\mathbf{2 Y}}$ & 18 & 338 & $\begin{array}{l}\text { more effort to join the } \\
\text { micro system more } \\
\text { effort to join the micro } \\
\text { system }\end{array}$ & $\begin{array}{l}\text { separate voltage } \\
\text { sources are required } \\
\text { fields voltage result } \\
\text { in a range 3-9 v }\end{array}$ \\
\hline Electromagnetic & $\mathbf{u}=\frac{\mathbf{B}^{2}}{2 \boldsymbol{\mu}_{\mathbf{0}}}$ & 17.7 & 335 & $\begin{array}{l}\text { separate voltage source } \\
\text { are required fields }\end{array}$ & $\begin{array}{l}\text { Compatible with } \\
\text { micro system }\end{array}$ \\
\hline Electrostatic & $\mathbf{u}=\frac{\mathbf{1}}{\mathbf{2 \varepsilon \mathbf { E } ^ { 2 }}}$ & 4.5 & 80 & voltage range 0.1-0.3 v & $\begin{array}{l}\text { no voltage source } \\
\text { required }\end{array}$ \\
\hline
\end{tabular}

bridges exhibit low frequency random vibrations (2 to $30 \mathrm{HZ}$ ) and weak excitations of 0.01 to $0.05 \mathrm{~g}$ [3]. huanghe cablestayed bridge (china) 1-2 0.015 however, on others bridge structures, vibrations are comparatively more severe with a frequency range of 1 to $5 \mathrm{HZ}$ and acceleration levels of 0.3 to $1.5 \mathrm{~g}$. from table 1 , it can be seen that in the vibrations of bridges, the overall frequency content is in fact between 0 and $40 \mathrm{HZ}$ and the overall various bridges are summarized in table 2. the maximum acceleration of bridge vibrations reported by sazonov et al. is $0.55 \mathrm{~g}$; however, the maximum frequency ( 40 $\mathrm{HZ}$ ) is recorded for the bridge reported by short and medium range bridges vibrate with frequency generally between 2 and 8 $\mathrm{HZ}$ and acceleration levels less than $0.1 \mathrm{~g}$ [some bridges exhibit low frequency random vibrations (2 to $30 \mathrm{HZ}$ ) and weak excitations of 0.01 to $0.05 \mathrm{~g}$, huanghe cable-stayed bridge (china) 1-2 0.015

Table-3 : bridge structures vibrations RECOVERY

\begin{tabular}{|l|l|l|}
\hline & Bridge frequency $($ HZ) & Acceleration $(\mathbf{g})$ \\
\hline rt11 (new york, usa) & 1 & 0.55 \\
Ferrite (sweden) & $14 \_15$ & 0.02 \\
Barrel springs & $2-30$ & $0.01-0.035$ \\
new arsta (sweden) & $1-5$ & $0.3-1.5$ \\
Komtur (berlin) & $2-2.6$ & $0-0.006$ \\
new carquinez (california, usa) & $2-30$ & $0.01-0.13$ \\
(north, france) & 20.05 & 0.05 \\
\hline
\end{tabular}

The main objective of the power electronics technology in the power conditioning circuit, is described in figure 1.2, it is to process and control the flow of electrical energy from the source to the load in such a way that energy is used efficiently. Maximum power is transferred from the source to the electrical load.
The power conditioning circuit the conversion and regulation of electrical 
voltage to appropriate levels for the loads. To ensure the continuity of operation of the load, even when the external power source is weak or temporarily essential, the extra energy already harvested must be stored in the rechargeable battery or in the super capacitor,. Depending on the conditions of the ambient energy source, characteristic of the energy collector , and the power supply to the load (i.e. the wireless sensor node and the control circuit),

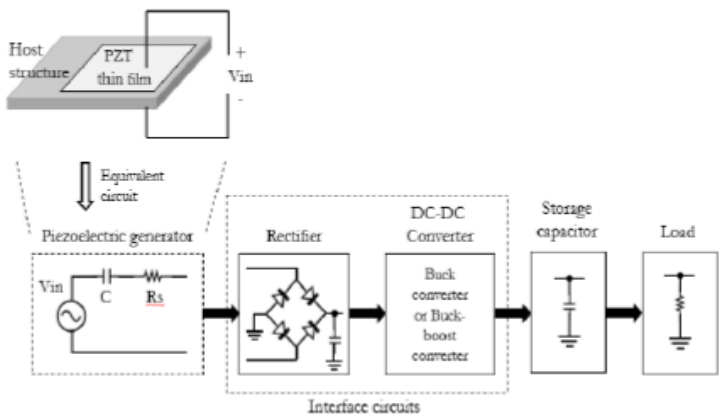

Figure 1.1 - structural diagram of a vibratory energy

\section{MODELIZATION OF PIÉZO CONTILEAVER}

the structure of a piezoelectric energy collector described in figure 2.1 consists of a beam whose one end is rigidly linked to the vibrating structure. a flyweight is placed at the other end, which amplifies the displacement. it adjusts the resonant frequency and increases the bandwidth. the piezoelectric elements are glued on one side (single morph) or on each side (dimorphic) of the beam, .. mode 31 [5] [6]. is used allows, thanks to the bending of the beam, to optimize the stress applied at the level of the beam. piezoelectric material, the piezoelectric generator can be modeled by a "mass + pole + spring + damper" assembly. ", figure 2.2. gives, the structure is equivalent to a mass $m$ resting both on a spring of stiffness $k$, representing the mechanical rigidity of the structure, on a damper or damping dissipator D (in $\mathrm{kg} / \mathrm{s}$ ), corresponding to the mechanical losses of the structure, and on an ideal piezoelectric element related to the structure. of the collector. table. 3 gives some examples of energy sources as well as their power densities $\alpha(\mathrm{N} / \mathrm{v})$ force factor, it is the ratio between the force Fp and the voltage $\mathrm{V}$ at zero strain. (the first equation reflects the dynamic equilibrium of the system and the voltage $\mathrm{V}$ at zero strain. (the first equation reflects the first equation eq(1) reflects the dynamic equilibrium of the system and the second corresponds to the displacement of mass is denoted by $\mathrm{x}, \mathrm{i}$ and $\mathrm{V}$ being the output current and voltage collected on the piezoelectric

$$
\left\{\begin{array}{c}
\mathbf{M} \ddot{\mathbf{x}}+\mathbf{D} \dot{X}+\mathbf{K p x}+\mathbf{k} \dot{\mathbf{X}}+\boldsymbol{\alpha} \mathbf{V}=\mathbf{F}_{\mathrm{E}} \\
\mathbf{I}=\boldsymbol{\alpha} \dot{\mathbf{x}}-\mathbf{C}_{\mathbf{0}} \dot{\mathbf{V}}
\end{array}\right.
$$

Fp is the force applied to the piezoelectric element. the equations are derived from the standard equations which relate the stress $\mathrm{T} 3$, the strain S3, the electric field E3 and the electric induction D3. they involve the geometric dimensions of the piezo element from the equations we can establish an equivalent electrical diagram of the generator the electrical part is separated from the mechanical part by a perfect transformer of gain $1 / \alpha \mathbf{K p}$ stiffness of the piezoelectric element when short-circuited, blocked capacitance $\mathbf{C}_{\mathbf{0}}$. of the dynamic equilibrium of the system and the

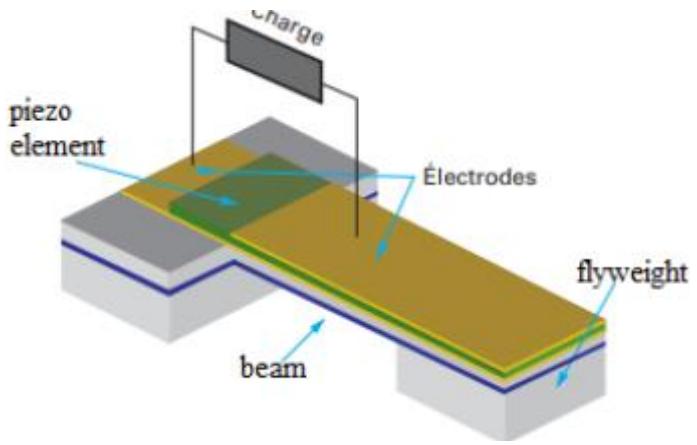

Figure 2.1- Configuration of piezoelectric energy

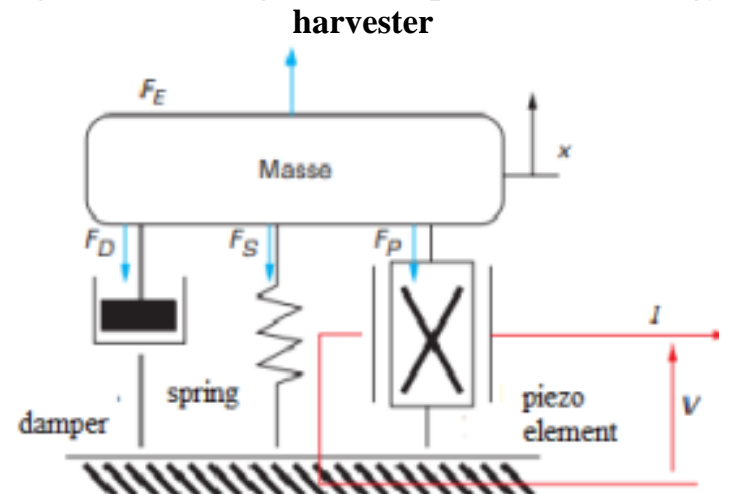

Figure 2.2 -Localized constant model of the generator

part is separated from the mechanical part by a perfect transformer of gain $1 / \alpha \mathbf{K p}$ stiffness of the piezoelectric element when short-circuited, blocked capacitance $\mathbf{C}_{\mathbf{0}}$. of the piezoelectric element, $\quad\left\{\begin{array}{l}\mathbf{F p}=\mathbf{K} \mathbf{p} \mathbf{x}+\boldsymbol{\alpha} \mathbf{V} \\ \mathbf{I}=\boldsymbol{\alpha} \dot{\mathbf{X}}-\dot{\mathbf{V}} \mathbf{C}_{\mathbf{0}}\end{array}\right.$

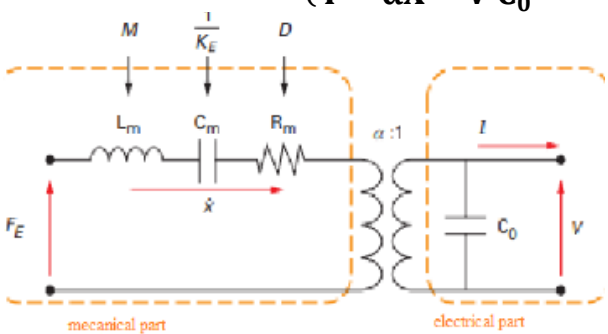

Figure 2.3 - Electrical diagram of piezo generator represented by a capacitance $\mathrm{cm}$, the mass $\mathrm{m}$ by an inductance $\mathrm{lm}$ and the damping by a resistance $\mathrm{r} \mathrm{m}$. the resonance frequency $\mathrm{f} 0$ is that of the mechanical structure and remains fixed whatever the load by analogy, in the mechanical branch the equivalent stiffness is $\mathrm{K}_{\mathrm{E}}=\mathrm{K}_{\mathrm{P}}+\mathrm{K}$ is represented by a capacitance $\mathrm{cm}$, the mass $\mathrm{m}$ by an inductance $\mathrm{Lm}$ and the damping by a resistance $\mathrm{R} \mathrm{m}$. the resonance frequency $f_{0}$ is that of the mechanical structure and remains fixed whatever the load

$$
f_{0}=\frac{1}{2 \pi} \sqrt{\frac{K p+K}{M}}=\frac{1}{2 \pi} \sqrt{\frac{1}{L m C m}}
$$

the expression of the output voltage is

$$
\mathbf{V}=\frac{\alpha \mathrm{RF}_{\mathrm{E}}}{\left(\alpha^{2} \mathbf{R}+\mathbf{D}\right)+\mathbf{j} \omega_{0} \mathbf{R D C}_{\mathbf{0}}}
$$

and the power is

$$
\mathrm{F}_{\mathrm{E}}{ }^{2} \frac{\alpha^{2} \mathrm{R}}{2} \frac{1}{\alpha^{4} \mathbf{R}^{2}+2 \alpha^{2} \mathrm{RD}+\mathrm{D}^{2}+\left(\omega_{0} \mathrm{RDC}_{0}\right)^{2}}
$$

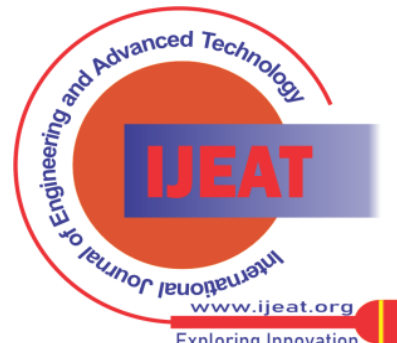




\section{Ltspice Simulation of Non Linear Technique SSHI Serial and SSHI Parallel of Piezoelectric Vibration Energy Harvesting}

in the case of a mechanical excitation maintained at the resonant frequency, the electrical diagram can therefore be given in fig 2.4. the associated waveforms are shown. the consumption of the circuit for which the electrical energy is intended is modeled by a resistor $r$. the current ie is the image of the speed of vibration at resonance the diagram can be simplified
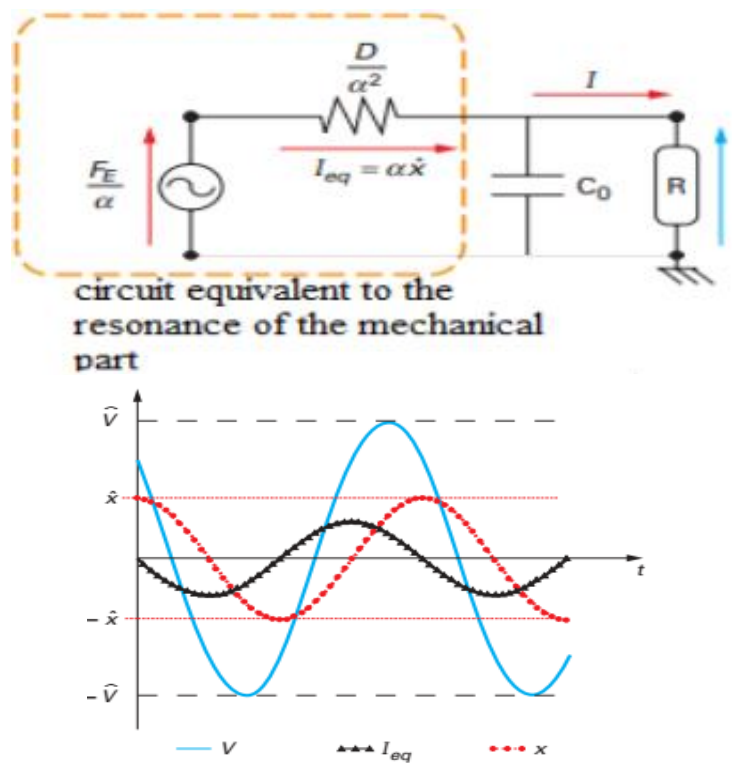

Figure 2.4 - Resonance electrical diagram and waveforms

The output power is

$$
P=-\frac{\alpha^{2} R \frac{F_{E}^{2}}{2 D^{2}}}{1+\left(\omega_{0} C_{0} R\right)^{2}}
$$

the force factor being very low, the maximum power is obtained for the resistance: $\mathbf{R o p t}=\frac{1}{\mathrm{C}_{0} \boldsymbol{\omega}_{0}}$

$$
\text { and its expression is: } \quad \mathbf{P}=-\frac{\alpha^{2} \mathbf{R F}_{\mathbf{E}}{ }^{2}}{\mathbf{4 C}_{\mathbf{0}} \boldsymbol{\omega}_{0} \mathbf{D}^{2}}
$$

the power is proportional squared of the applied force or of the acceleration $\gamma \quad\left(\mathbf{F}_{\mathbf{E}}=\mathrm{m} \gamma\right)$ and inversely proportional to the vibration frequency fig 2.5 shows the equivalent circuit of cantilever piezoelectric energy harvesters [7]. this simplified model can be used in the case where the force

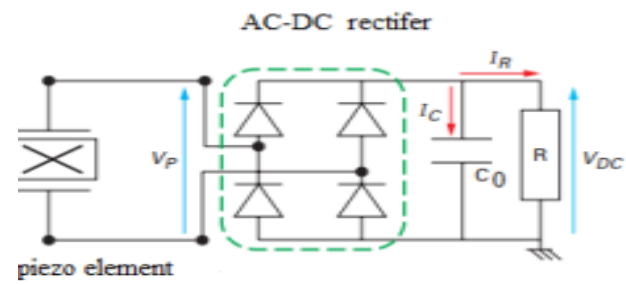

coupling factor is weak and the piezoelectric voltage doesn't have a significant effect on the vibration behavior of the structure. the input vibration is modeled by a current source $\alpha \dot{\mathbf{x}}, \dot{\mathbf{x}}$ is the velocity of the vibration, the force-voltage coupling factor $(\alpha)$ determines the energy conversion of the piezoelectric from the vibration to the electric voltage and $\mathrm{Cp}$ is clamped capacitance of the piezoelectric element this model will be adopted for the simulation suite of non-linear techniques with lt spice. once the $\mathrm{PEH}$ is excited, an internal piezoelectric alternating current $\alpha \mathrm{x}^{*}$ charges and discharges the inherent capacitor $\mathrm{Cp}$, generating a voltage $\mathrm{Vp}$ across the PEH (10) (fig.3.1). in order to power a full bridge diode rectifier (FBR) (8) is used to rectify the voltage Vp, energy can be extracted regardless of the type and frequency of excitation, as long as Vp exceeds the output buffer voltage VDC. however, this energy extraction is only optimized when VDC is equal to half of the peak open circuit voltage $\mathrm{PEH}$ vpoc the period is denoted $\mathrm{T}$, the instants $\mathrm{T}_{1}$ and $\mathrm{T}_{3}$ correspond to the passage through zero of the speed of vibration, or even to the minimum and the maximum of the displacement. during a half-period, we can therefore write the following relation:

$\int_{\mathrm{T}_{1}}^{\mathbf{T}_{2}} \dot{\mathbf{V}} \mathbf{d t}=\mathbf{V}_{\mathrm{DC}}-\left(-\mathbf{V}_{\mathrm{DC}}\right)=\mathbf{2} \mathbf{V}_{\mathrm{DC}}$ the second equation thus gives $\int_{\mathbf{T}_{\mathbf{1}}}^{\mathbf{T}_{3}} \mathbf{I d t}=\frac{\mathbf{V}_{\mathbf{D C}}}{\mathbf{R}} \frac{\mathbf{T}}{\mathbf{2}} \quad$ the output voltage is given in eq (3) $\mathbf{V}_{\mathrm{DC}}=\frac{2 \mathrm{R} \alpha \omega_{0}}{\pi+2 \mathrm{RC}_{0} \omega_{0}} \widehat{\mathbf{X}}$

therefore depends on the maximum displacement $\widehat{\mathbf{X}}$. to express it as a function of the applied force $F_{E}$, the assumptions are: - first, the resonant frequency is that of the structure, electric; - then, we neglect the termVin the first equation $\mathbf{F}_{\mathbf{E}}=\mathbf{D} \boldsymbol{\omega}_{\mathbf{0}} \widehat{\mathbf{X}}$ therefore

$P=\frac{V_{D C}^{2}}{R}=\frac{4 \alpha^{2} R}{\left(2 \omega_{0} R_{0}+\pi\right)^{2}} \frac{F_{E}^{2}}{D^{2}}$

the power is obtained in eq (4) for the resistance: and its expression is it should be noted that during operation at maximum power with the impedance matching, time $T_{2}$ is equal to the maximum power

$$
\mathbf{P}_{\mathrm{MAX}}=\frac{\alpha^{2}}{2 \omega_{0} \mathrm{RC}_{0}} \frac{\mathrm{F}_{\mathrm{E}}{ }^{2}}{\mathrm{D}^{2}}
$$

. it noted that when operating at maximum power with the impedance matching, the instant $\mathrm{T}_{2}$ is equal to $\mathrm{T} / 4$
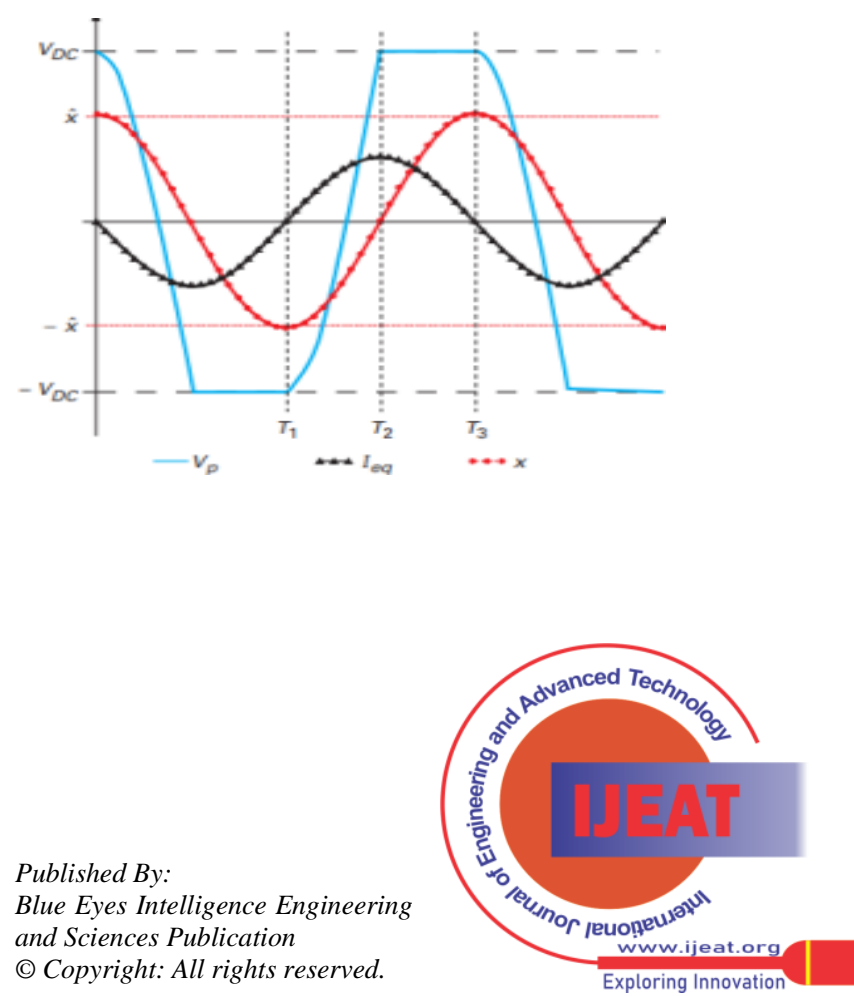


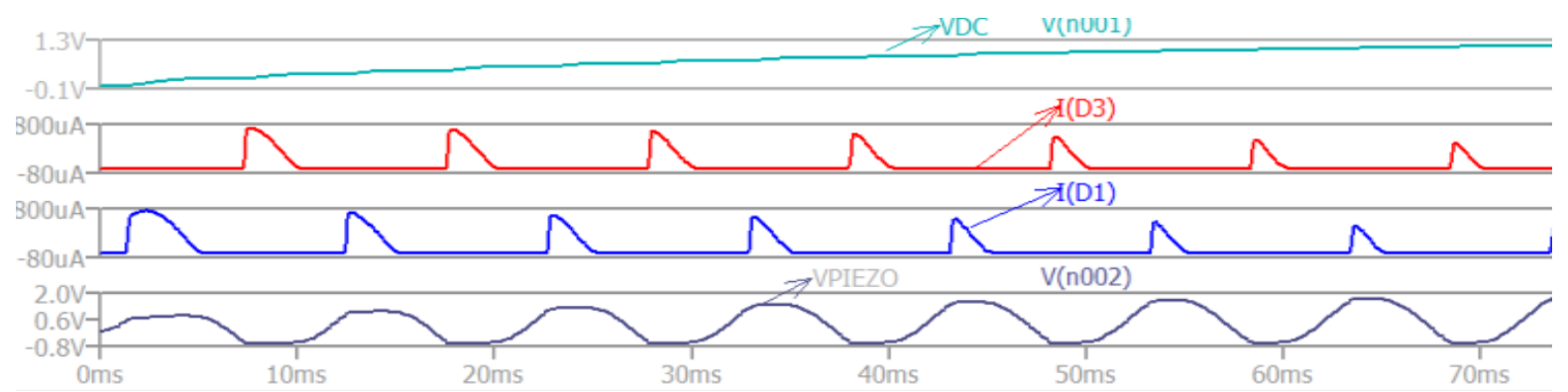

figure 2.5 -Standard energy recovery and wave forms for standard technical $I p=800 \mu A \quad c_{0}=470 \mathrm{nF} \quad R=100 \mathrm{k} \Omega$ $\mathbf{f}=20 \mathrm{HZ}$ PDC $=16.9 \mu \mathrm{w}$

\section{TECHNIQUES SSHI (SYNCHRONIE SWITCH HARVESTINGS ON INDUCTION):}

\section{1 Parallel SSHI :}

The principle of non linear optimization is based on the addition of a switch in series or in parallel with an inductor. the switch is briefly closed at each extremum of the deformation to phase the voltage across the piezoelectric and the speed of vibration, and therefore minimize the energy stored in the capacitor $C_{0}$..[9]. [10] to increase the accumulation of electric charges on the parallel SSHI electrode: the diagram of the piezoelectric element and of the parallel SSHI circuit,

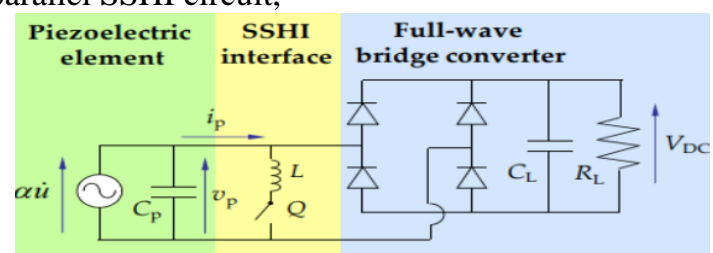

as well as the associated waveforms are presented in figure 3.1 .

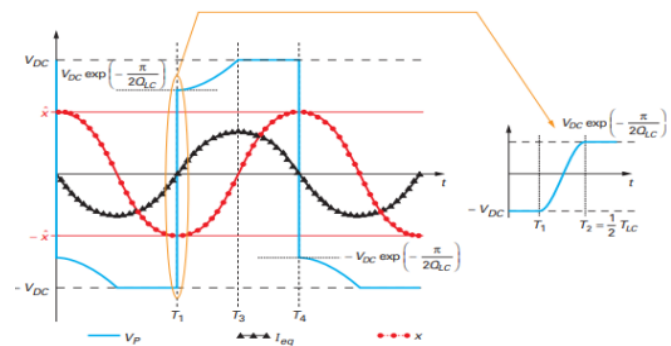

figure3.1-Parallel SSHI technique diagram and waveforms

$\mathrm{T} 1$ and T4 correspond to the zero crossing of the vibration speed at the instant $\mathrm{T} 1$, the switch $\mathrm{k}$ is closed, the inductance $\mathrm{l}$ and the internal capacitance c0 of the piezoelectric element start to oscillate, the current ip and the vp voltage then evolve sinusoid ally halfway through the Tlc oscillation period

$$
\text { T lc }=\pi \sqrt{\mathrm{LCp}}
$$

(instant T2), [5] the current is canceled out (unidirectional current circuit) and the voltage reaches the value

$$
\begin{aligned}
& V\left(\frac{T_{L C}}{2}\right)=V_{D C} \exp \left(\frac{-\pi}{\sqrt{\left(2 Q_{L C}\right)^{2}-1}}\right) \approx V_{D C} \exp \left(\frac{-\pi}{2 Q_{L C}}\right) \\
= & V_{D C} q_{l c} \text { with } q_{l c}=\exp \left(\frac{-\pi}{2 Q_{L C}}\right)
\end{aligned}
$$

with $\mathbf{Q}_{\mathbf{L C}}=\frac{\mathbf{1}}{\mathbf{R}} \sqrt{\frac{\mathbf{L}}{\mathbf{C p}}}>>1$ is the quality factor of the resonant circuit $r$ is the serial resistance of the coil added to the resistance of the switch .

$$
\begin{gathered}
\int_{\mathrm{T}_{1}}^{\mathrm{T}_{4}} \mathrm{Idt}=2 \alpha \hat{\mathrm{x}}-\mathrm{c}_{0}\left(1-\mathrm{q}_{\mathrm{lc}}\right) \mathrm{V}_{\mathrm{DC}}=\frac{\mathrm{V}_{\mathrm{DC}}}{\mathrm{R}} \frac{\mathrm{T}}{2} \\
\mathrm{~V}_{\mathrm{DC}}=\frac{2 \mathrm{R} \alpha}{\pi+\left(1-\mathrm{qlc}_{\mathrm{lc}}\right) \mathrm{RC}_{0} \omega_{0}} \frac{\mathrm{F}_{\mathrm{E}}}{\mathrm{D}} \\
\mathrm{P}=\frac{\mathrm{V}_{\mathrm{DC}}{ }^{2}}{\mathrm{R}}=\frac{\mathrm{F}_{\mathrm{E}}{ }^{2}}{\mathrm{D}^{2}} \frac{4 \mathrm{R} \alpha^{2}}{\left(\pi+\left(1-\mathrm{q}_{\mathrm{lc}}\right) \mathrm{RC}_{0} \omega_{0}\right)^{2}} \\
P \max =\frac{\mathrm{F}_{\mathrm{E}}{ }^{2}}{\mathrm{D}^{2}} \frac{\alpha^{2}}{\left(\pi+\left(1-\mathrm{q}_{\mathrm{lc}}\right)\right)^{2}}
\end{gathered}
$$

the maximum power is obtained for the resistance:

$$
\begin{aligned}
& \mathbf{R}_{\mathbf{o p t}}=\frac{\boldsymbol{\pi}}{\left(\mathbf{1}-\mathbf{q}_{\mathbf{l c}}\right) \mathbf{C}_{\mathbf{0}} \boldsymbol{\omega}_{\mathbf{0}}}, \mathrm{T}_{3} \text { is equal to } \mathrm{T} / 4 \text { the block diagram } \\
& \text { simulation with ltspice is given in fig } 3.2
\end{aligned}
$$

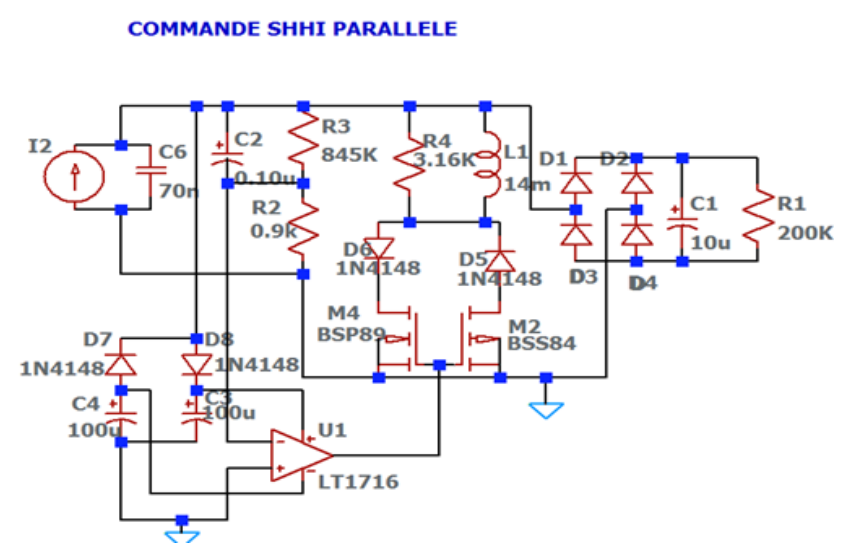

Published By:

Blue Eyes Intelligence Engineering

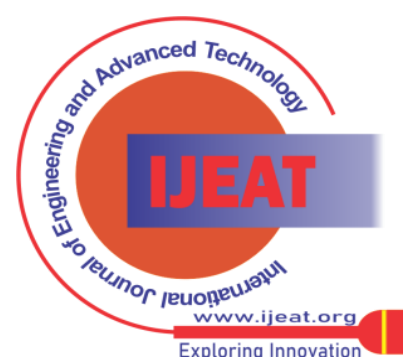




\section{Ltspice Simulation of Non Linear Technique SSHI Serial and SSHI Parallel of Piezoelectric Vibration Energy Harvesting}

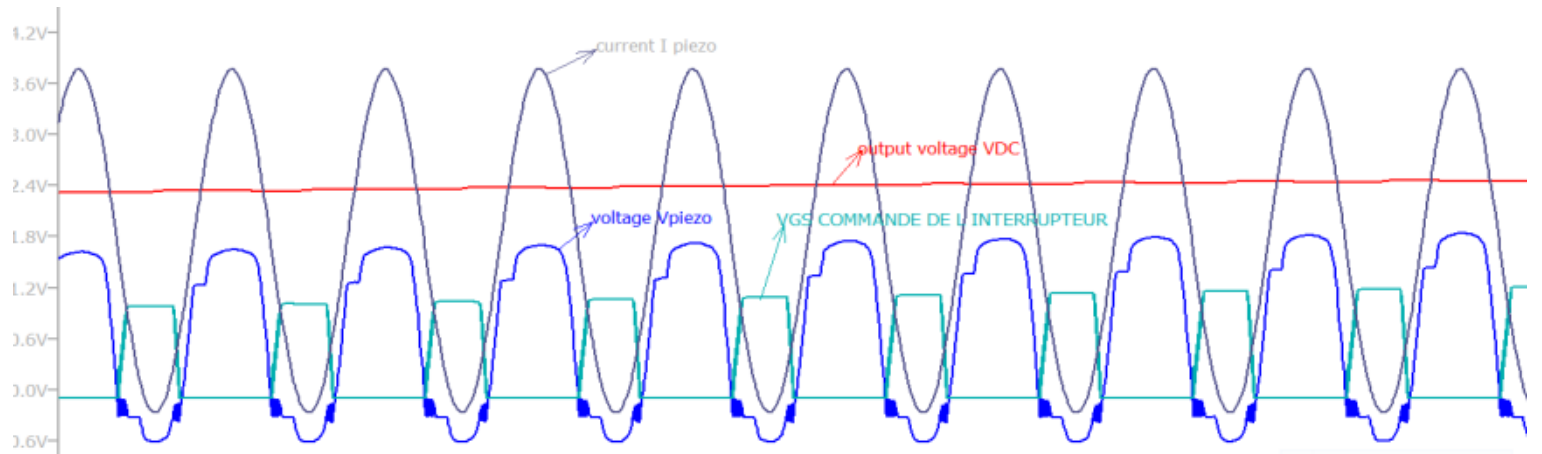

Figure 3.2-Waves signals parallel SSHI technique $\mathrm{R}=100 \mathrm{k} \Omega$

$\mathrm{r}=336 \Omega \quad \mathrm{l}=14 \mathrm{mH} \quad \mathrm{cp}=14 \mathrm{nF} \quad \mathrm{ql}=0.36 \quad \mathrm{p}=57 \mu \mathrm{W}$ cs $=10 \mu \mathrm{F}$

qlc inversion coefficient after simulation we retain the likelihood of the signals between the theoretical and practical signals for parallel SSHI control

32 Serial SSHI :

serial SSHI diagram, this nonlinear optimization technique, and associated waveforms are shown in figure 3. 3 .[11] .[12] this version has the drawback of transferring energy only for a very short time (closing time of $\mathrm{k}$ ), corresponding to the half-period of oscillation of the circuit lc the average current at the output of the piezoelectric element during half a period of mechanical oscillation is equal to the average current in the load

$$
\begin{aligned}
& \int_{T_{1}}^{T_{4}} I d t=c_{0}\left(\left(V_{P}-V_{D C}\right)\left(1+q_{l C}\right) V_{D C}\right. \\
& =\frac{V_{D C}}{R} \frac{T}{2}
\end{aligned}
$$

the expression of the output voltage as a function of the amplitude of the applied force is therefore

$$
V_{D C}=\frac{2 R \alpha\left(1+q_{l c}\right)}{\left(1-q_{l c}\right) \pi+2\left(1+q_{l c}\right) R C_{0} \omega_{0}} \frac{F_{E}}{D}
$$

the

$$
\begin{gathered}
P_{D C}=\frac{\left(\frac{2 R \alpha\left(1+q_{l c}\right)}{\left(1-q_{l c}\right) \pi+2\left(1+q_{l c}\right) R C_{0} \omega_{0}} \frac{F_{E}}{D}\right)^{2}}{R} \\
P_{M A X}=\frac{F_{E}^{2}}{D^{2}} \frac{\alpha^{2}\left(1+q_{l c}\right)}{2 \pi C_{0} \omega_{0}\left(1-q_{l c}\right)}
\end{gathered}
$$

$$
\text { for } R_{o p t}=\frac{\left(1-q_{l c}\right) \pi}{2\left(1+q_{l c}\right) C_{0} \omega_{0}}
$$

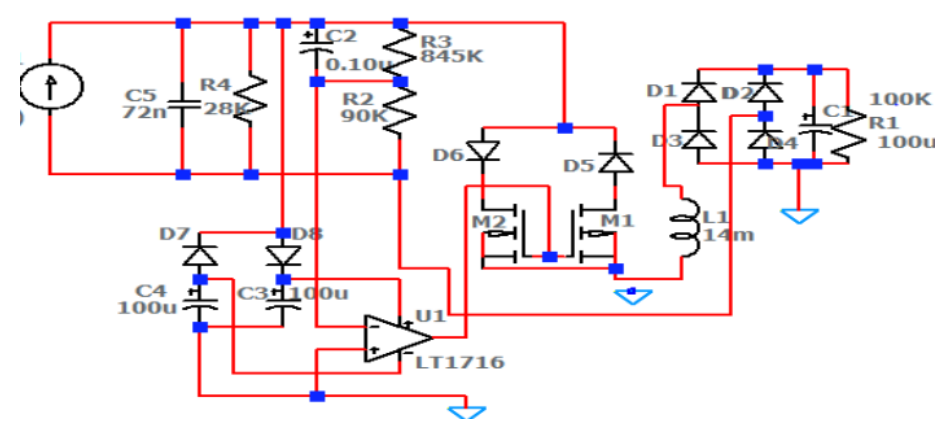

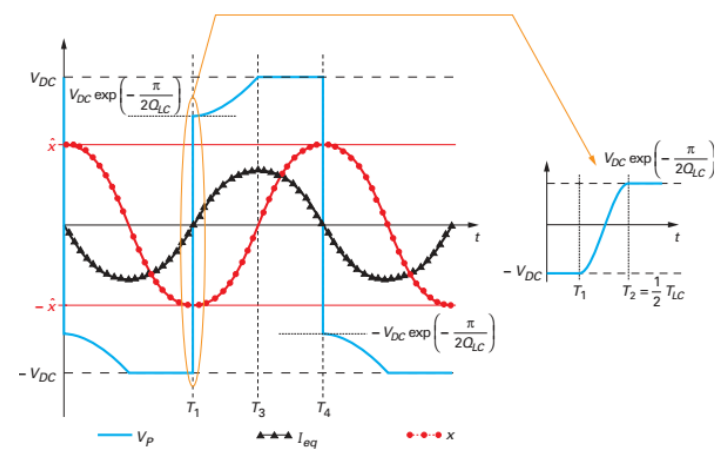

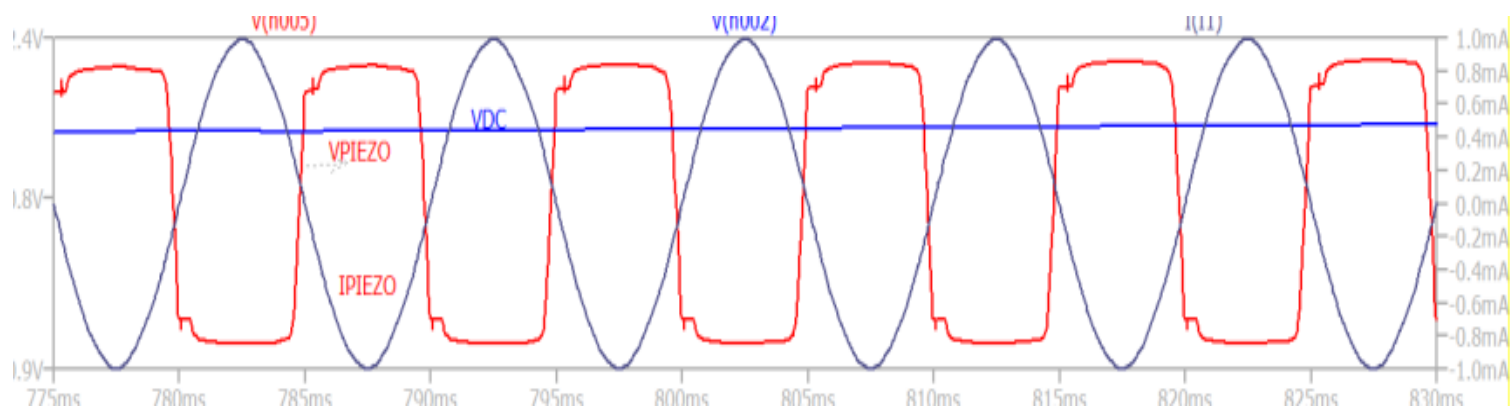

Tigure 3.3 Diagram and waveforms of the SSHI serial technique

$$
\begin{gathered}
P_{D C}=\frac{\left(\frac{2 R \alpha\left(1+q_{l c}\right)}{\left(1-q_{l c}\right) \pi+2\left(1+q_{l c}\right) R C_{0} \omega_{0}} \frac{F_{E}}{D}\right)^{2}}{R} \\
P_{M A X}=\frac{F_{E}{ }^{2}}{D^{2}} \frac{\alpha^{2}\left(1+q_{l c}\right)}{2 \pi C_{0} \omega_{0}\left(1-q_{l c}\right)}
\end{gathered}
$$

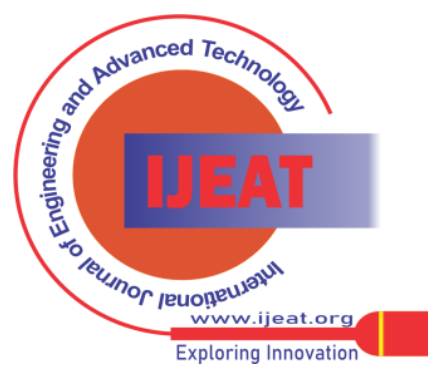


3.3. Comparison

$$
\text { for } R_{o p t}=\frac{\left(1-q_{l c}\right) \pi}{2\left(1+q_{l c}\right) C_{0} \omega_{0}}
$$

the variation in power, normalized compared to the power obtained with the rectifier bridge without SSHI, as a function of the load resistance standardized for the different energy recovery techniques. the interest of SSHI techniques is clearly evident there. [13] these graphics are independent of the model parameters. only the qlc inversion coefficient is needed for the plot. practically, it is difficult to obtain a value of qlc greater than 0.7 , which corresponds to an increase in the power of a ratio 8 it should be noted that this technique is interesting for weakly coupled structures or during operation outside the resonant frequency. with the values obtained during the simulation, we obtain results close to the theoretical results, noting moreover the tests are carried out for load resistances different from the optimal resistance giving maximum powers

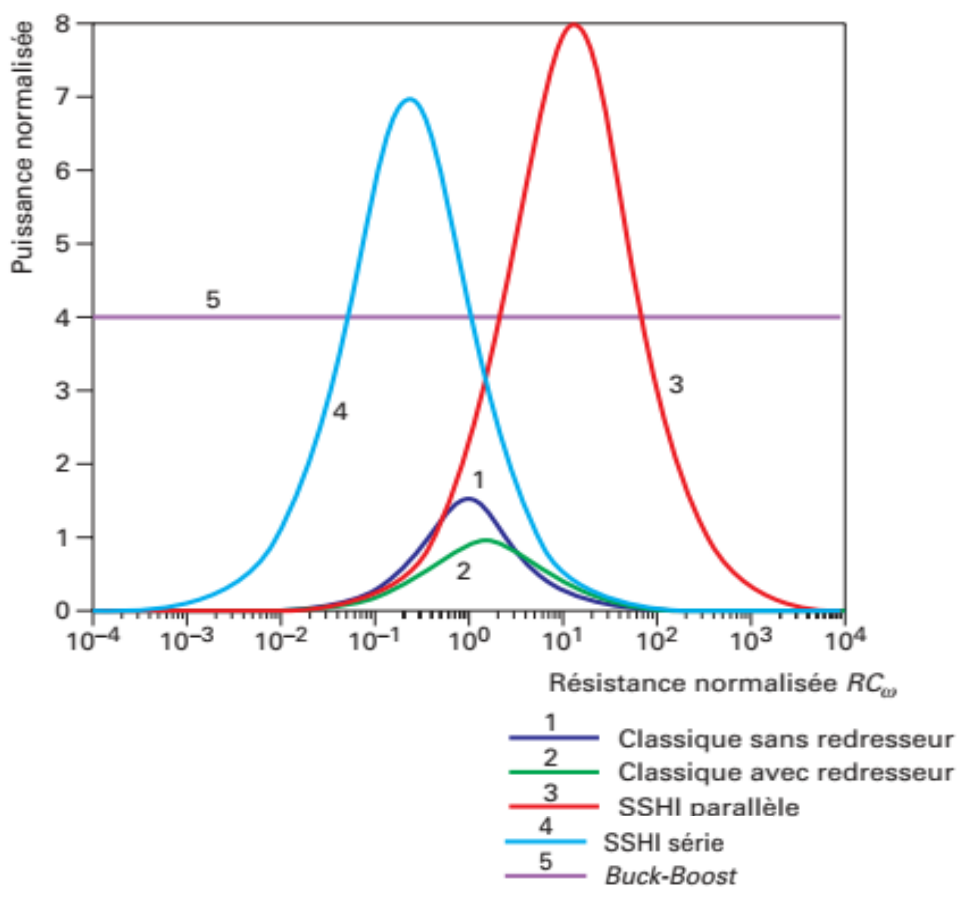

Table 3 -Comparison of technics for $q_{\mathrm{lc}}=\mathbf{0 . 6}$

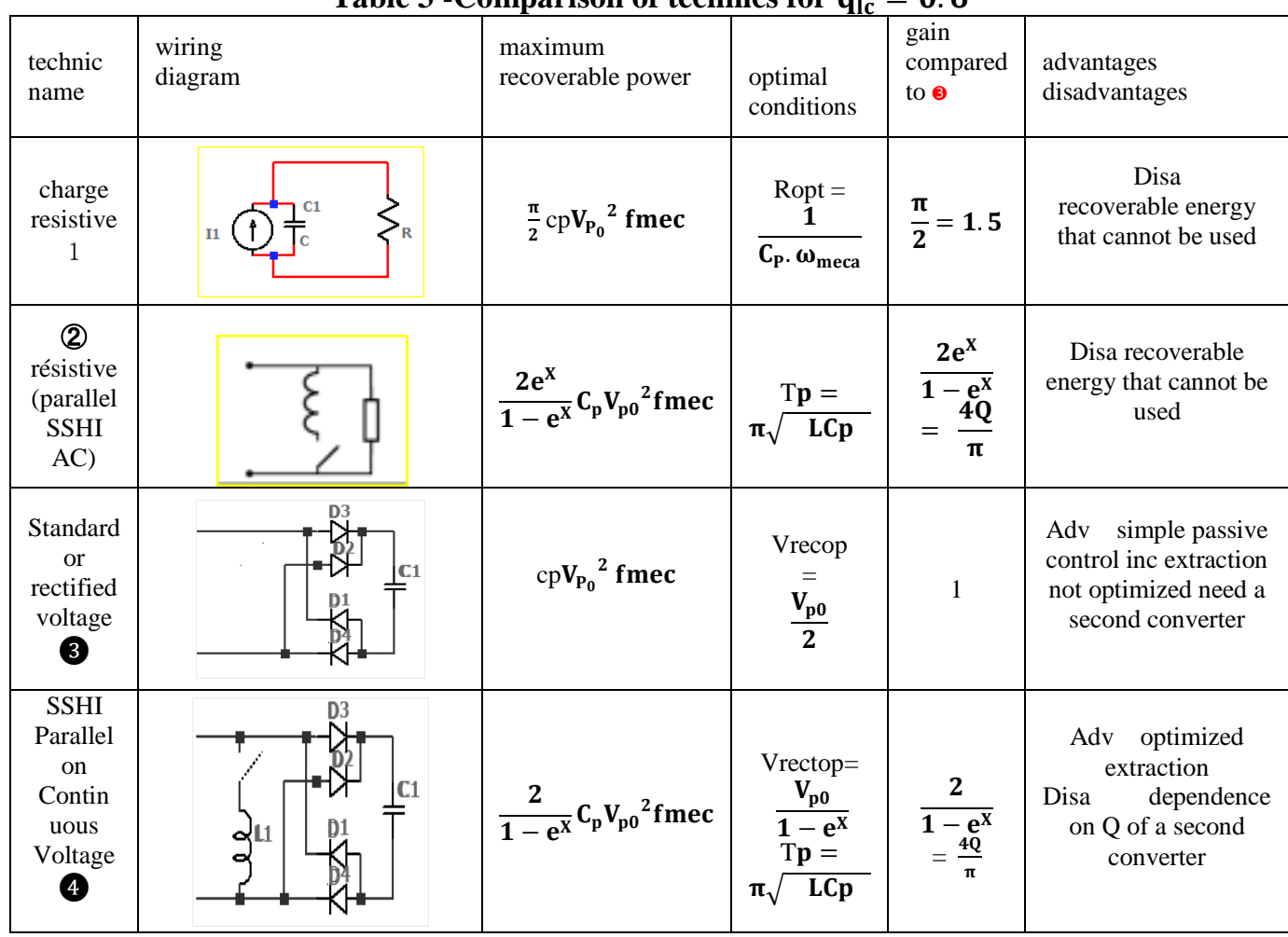

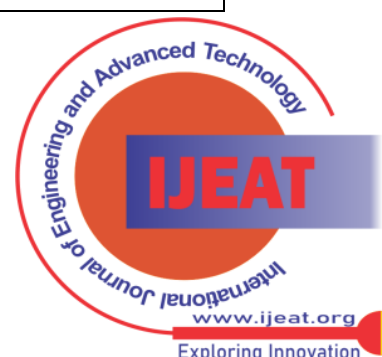




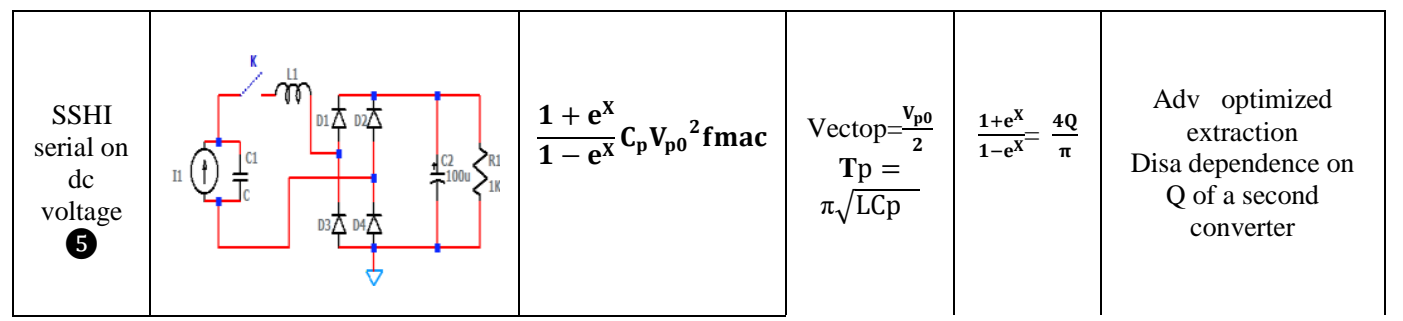

\section{CONCLUSION}

the SSHI circuit, has also been explored for the even strongly mechanically nonlinear and broadband structure. We know that the SSHI circuit increases the output power for weakly coupled, structurally (i.e. mechanically linear energy collectors). In this work we studied the performance of both serial SSHI circuits and with parallel SSHI . It has been observed that SSHI circuit can increase the output voltage of the branch of great amplitude for certain frequencies compared to the linear resistive loading. we could see the amplification factor of the output power 8 between the parallel sshi technique and the standard rectifier,only technique the impedance adaptation is always solicit in order to supply a maximum power to the load circuit WSN which is studied theoretically and carried out in simulation

\section{REFERENCES}

1. KHALIGH, Alireza, ZENG, Peng, et ZHENG, Cong. Kinetic energy harvesting using piezoelectric and electromagnetic technologiesstate of the art. IEEE transactions on industrial electronics, 2009, vol. 57, no 3, p. 850860.

2. WANG, Haoyu, TANG, Yichao, et KHALIGH, Alireza. A bridgeless boost rectifier for low-voltage energy harvesting applications. IEEE transactions on power electronics, 2013, vol. 28, no 11 , p. 5206-5214

3. DING, You-liang, LI, Ai-qun, MIAO, Chang-qing, et al. Finite Element Modeling of the Tower of runyang cable-stayed Bridge Based on Ambient Vibration Test. Journal of Highway and Transportation

4. SUN, Ying-jie, XIAO, Hai-zhu, et XU, Wei. Research of key techniques for construction control of Zhengzhou Huanghe River railcum-road bridge. Bridge Construction, 2011, vol. 2, p. 5-8.

5. VASIC, Dejan et COSTA, François. Applications des éléments piézoélectriques en électronique de puissance. Techniques de l'ingénieur, Composants actifs en électronique de puissance. Techniques de l'ingénieur, 2011, p. 235-24.

6. VASIC, Dejan et COSTA, François. Applications des éléments piézoélectriques en électronique de puissance. Techniques de l'ingénieur, Composants actifs en électronique de puissance. Techniques de l'ingénieur, 2011, p. 235-24.

7. DU, Sijun et SESHIA, Ashwin A. An inductorless bias-flip rectifier for piezoelectric energy harvesting. IEEE Journal of Solid-State Circuits, 2017, vol. 52, no 10, p. 2746-2757

8. UD DIN, Amad, KAMRAN, Muhammad, MAHMOOD, Waqar, et al. An efficient CMOS dual switch rectifier for piezoelectric energyharvesting circuits. Electronics, 2019, vol. 8, no 1, p. 66.

9. CHAMANIAN, Salar, ZORLU, Özge, KÜLAH, HALUK, et al. A self-powered integrated interface circuit for low power piezoelectric energy harvesters. In : 2013 4th Annual International Conference on Energy Aware Computing Systems and Applications (ICEAC). IEEE, 2013. p. 45-

10. LAERMER, Franz, PANNEK, Thorsten, REICHENBACH, Ralf, et al. Bending transducer device for generating electrical energy from deformations and circuit module. U.S. Patent No 8,154,174, 10 avr. 2012

11. GUYOMAR, Daniel, BADEL, Adrien, LEFEUVRE, Elie, et al. Toward energy harvesting using active materials and conversion improvement by nonlinear processing. IEEE transactions on ultrasonics, ferroelectrics, and frequency control, 2005, vol. 52, no 4, p. 584-595.

12. PADMAVATHY, C., JAYASHREE, L. S., et ROSARIO, A. Combined vibration and RF harvester technique for energy

\section{AUTHORS PROFILE}

Mountaciri abderrahim is Professor of electronics leaving the ENSET of MOHAMMEDIA in 1993, associate professor in electrical engineering in 2005 of the ENSET RABAT practicing since 2007 in the preparatory class of the large engineering schools in settat moroc, these recharges are done in energy and telecom network

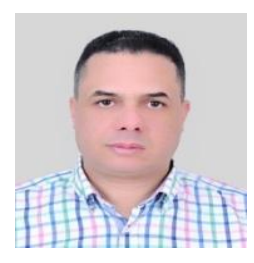

El Mostafa MAKROUM is Professor in the faculty of the sciences and technology of Settat, Morocco. He received his M.S. degree in 2007 from the Mohammadia School of Engineering, University Mohammed V, Rabat, Morocco. He received his Ph.D. degree in Computers and Telecommunications from the Higher National School of Electricity and Mechanics, University Hassan II, Casablanca, Morocco. His current research concerns RFID antennas, propagation and EMC problems

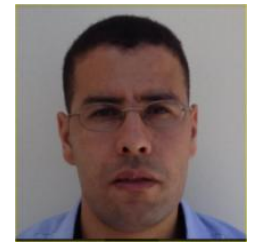

My Abdelkader Youssefi received his engineering degree in telecommunications from $\mathrm{Na}$ tional Institute of Telecommu nications (INPT), Rabat, Mo rocco, in 2003, and received his Ph.D. degree from Mohamma dia School of Engineers (EMI) at Mohammed V University in 2015. Between September 2003 and May 2016, he worked as a telecommunications engineer. Currently, Youssefi is a teacher at Hassan I University, Settat, Morocco. His re search interests include cognitive radio, channel estimation, massive MIMO, OFDM and Internet of Things security in wireless networks.

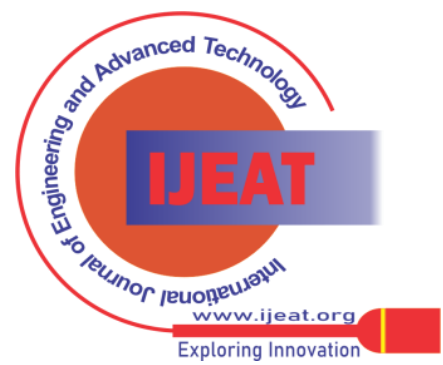

